\title{
Measurement of Calibrated Recursive Analytic in the Gas Tungsten Arc Weld Pool Model
}

\section{Temperature distribution is correlated to its history and newly applied arc energy}

\author{
BY S. J. WU, H. M. GAO, W. ZHANG, AND Y. M. ZHANG
}

\begin{abstract}
An analytic model based on a single-ellipsoidal stationary heat source can estimate the penetration in gas tungsten arc welding (GTAW) accurately with the calibration from the 3D measurements of the weld pool surface. However, the computation needed for the integration associated with the analytic model increases with time and when the current is changed; its real-time application is no longer feasible. To address this challenge, the basic principles on which the analytic model was derived were analyzed to rebuild a modified analytic model. In this rebuilt model, the temperature distribution was expressed into two terms: one as a function of an earlier temperature distribution, and the other as a function of the newly applied arc power. With this rebuilt anaIytic model, a recursive solution was facilitated such that the computation does not increase/change as the welding time increases and the desirable real-time computation and calibration can be obtained. To further reduce the computation time, a model was fit for the earlier distribution as given by discrete points such that its function can be analytically evaluated to minimize the needed online computation. Experiments were performed where cross sections of the welds were used to verify the novel recursive model calibrated by the measurements of the $3 \mathrm{D}$ weld pool surface.
\end{abstract}

\section{KEYWORDS}

- Gas Tungsten Arc Welding (GTAW) • Analytic Model

- Weld Penetration • Weld Pool • Three-Dimensional Vision (3D)

\section{Introduction}

This work is a continuation of our recent efforts (Refs. 1, 2) to establish the scientific foundation for monitoring how deeply a developing weld pool has penetrated underneath the workpiece during gas tungsten arc welding (GTAW). Since the depth of the weld pool is not directly measurable, various techniques, including vision sensing (Refs. 3-7), pool oscillation (Refs. 8-11), ultrasound (Refs. 12-16), and infrared (Refs. 17-19) have been proposed to obtain indirect measurements. Efforts have been taken to interpret them by characterizing the weld pool surface (such as width, length, and convexity) from vision sensing (Refs. 20-22), analyzing process parameters (such as current, voltage, and speed) (Refs. 23-26), or modeling human welder responses to the dynamic weld pool surface (Refs. 27-30) to better correlate the measurements to the penetration of the weld pool. Analytic models have also been proposed to control the penetration as calibrated by online measurements (Ref. 31 ), but the relation between the measurements and the analytic model parameters is empirical.

In our recent efforts (Refs. 1, 2), a different approach was taken with the hope that the penetration and measurements may be better correlated based on a more solid scientific foundation. This approach used an analytic model to compute the temperature distribution and then calibrated it using measured weld pool surface. To this end, Nguyen's single-ellipsoidal stationary, heat-source based analytic solution (Ref. 32) was used to provide an initial temperature distribution in the workpiece. The computed weld pool radius stationary welding was compared with that from the measurement. The temperature distribution was then shrunk/expanded through an adjustment ratio in the radius direction ( $x-y$ directions) such that the error of the computed radius with the measurement became zero. The calibrated temperature distribution was then used to compute the increase in the volume due to thermal expansion. The resultant volume was then compared with that from the measurement on the weld pool surface. The temperature distribution was shrunk/expanded again but in the depth direction such that the volume error also became zero. The temperature distribution was thus fully calibrated in all directions.

The above-mentioned analytic model was developed, calibrated, and verified under a given constant current and a uniform preheating temperature. Its ability to predict the penetration depth accurately has been verified through comparison with the measured cross sections of welds. While this calibrated analytic model may predict the penetration depth and be used to produce the desirable penetration depth, developing the weld pool including weld width and penetration in desirable ways within the desired time re- 


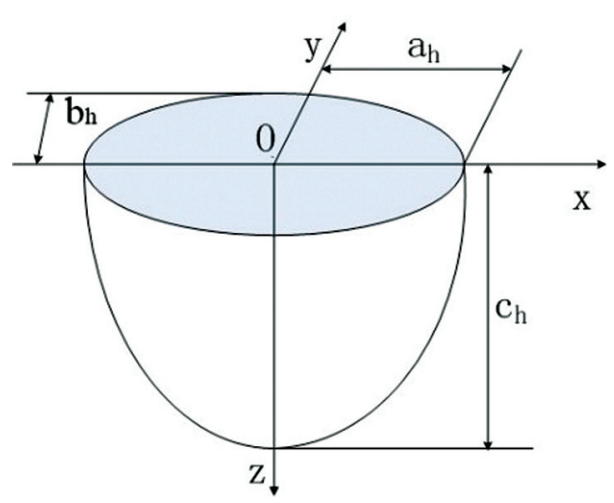

Fig. 1-Sketch of Goldak's body heat source (Ref. 34).

quires real-time adjustments on the arc power/current. Analytic models thus need to derive for a varying current, and this work is devoted to addressing this issue as a continuation of our recent efforts in using analytic computation and calibration methods to correlate measurements to weld penetration based on a solid scientific foundation.

Using the analytic model, the temperature distribution at $t_{f}>0$ can be computed as an integral from the initial time to the current time $t_{f}$. Since the function to be integrated changes with $t_{f}$, the integration over the entire time period $\left[0, t_{f}\right]$ is computed each time as the time $t_{f}$ changes/goes. Integrations/computations in different times are not correlated and the computation for the integration increased with the time. For a given constant current, all the computations may be performed offline in advance and the computed temperature distributions at different times are stored. However, when the current varies, computing and storing temperature distributions in advance is no longer feasible.

To address the challenge from the continuously increasing computation, the authors wondered if the temperature distribution may be analytically correlated to an earlier distribution and newly applied current. With such a correlation, a recursive solution may be facilitated such that the computation does not increase or change with the time. Not only can large storage be avoided, but also real-time computation and calibration can be obtained.

Obtaining this needed analytic correlation is challenging because the previous methods used for derivations are not fully and directly applicable, in particular the constant current and initial temperature field. To address this challenge, the authors first analyzed the basic principles that the previous derivations were based on and applied them to the new conditions to derive an analytic model that works under varying current. Then the analytic model, also as an integration over time, was decomposed into integrations in two different time intervals. Further analysis led to the favorable result that they are separately determined by an earlier temperature distribution history and the newly applied arc energy.

More excitingly, the authors analyzed the two terms and found they are the spatial convolution of the earlier temperature distribution with the heat source distribution and the multiplication of a fixed integration with the newly applied current (arc energy). While the fixed integration can be computed in advance, the spatial convolution cannot because the

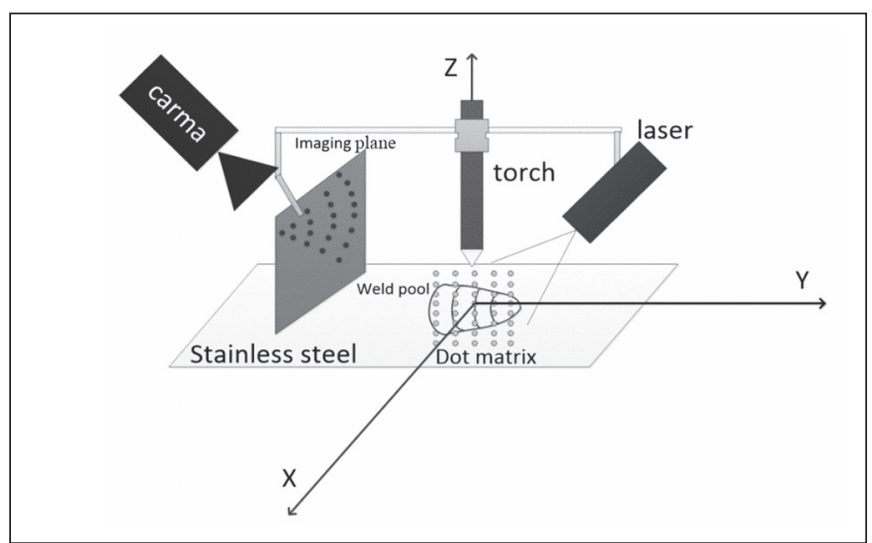

Fig. 2 - Monitoring of the weld pool surface using a lowpower illumination laser.

earlier temperature distribution varies. Numerical evaluation of the convolution is still computationally intensive. To obtain an analytic solution for the convolution, the earlier temperature distribution is used to fit an analytic description. With the analytic description for the earlier temperature distribution, its convolution with the heat source distribution, given analytically, can be analytically solved to minimize the needed computation.

This paper is organized as follows. In the "Analytic Model" section, the analytic model for varying current is derived. The "Experimental Procedure" section describes the observation system and experimental conditions. The calibrated penetration and its experimental identification are shown in the "Verification and Analysis" section. And, finally, conclusions are drawn in the "Conclusions" section.

\section{Analytic Model}

The analytic model to compute the temperature distribution evolution $T(x, y, z) t=t_{f}$ (the temperature distribution at time $t_{f}$ ) for a point heat source is derived by Rosenthal (Ref. 33). This derivation is enabled through the following approximations/principles: 1) plate thickness being infinite; 2) heat transfer being conductive; 3 ) initial temperature being uniform; and 4) effects of the continuous heat applied at the different times being summable through the superposition principle. The derivation starts with applying the superposition principle to obtain the temperature distribution $G(x, y, z)_{t}$ as the unit response of the heat source is continuously applied in $[0, \mathrm{t}]$ :

$$
\begin{aligned}
G(x, y, z)_{t} & =\int_{0}^{t} \frac{1}{(4 \pi a(t-\tau))^{3 / 2} \rho c} \cdot \exp \frac{x^{2}+y^{2}+z^{2}}{4 a(t-\tau)} d \tau \\
& =\left(\frac{1}{\rho c}\right) \int_{0}^{t} \frac{1}{(4 \pi a(t-\tau))^{3 / 2}} \cdot \exp \frac{x^{2}+y^{2}+z^{2}}{4 a(t-\tau)} d \pi \\
& =\left(\frac{1}{\rho c}\right) \int_{0}^{t} g(x, y, z)_{t-\tau} d \tau
\end{aligned}
$$




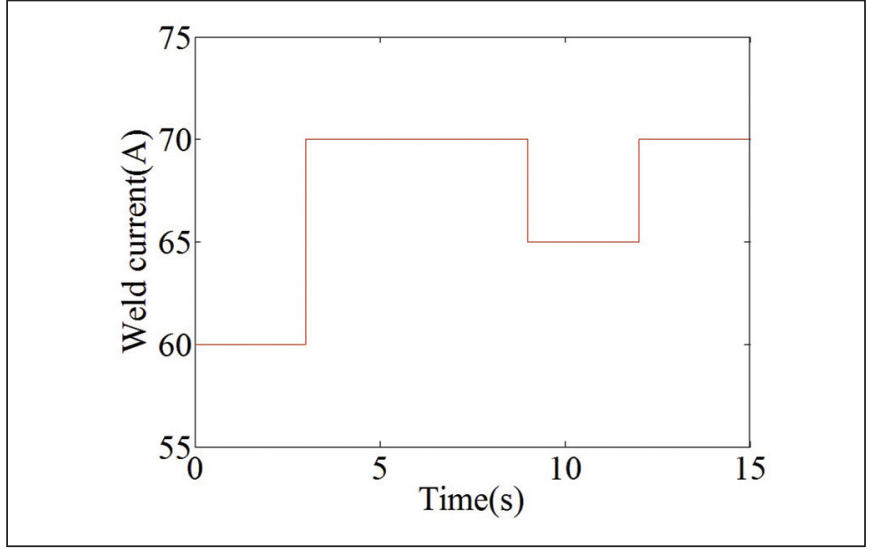

Fig. 3 - Welding current used in the verification experiment.

where $g(x, y, z)_{t}=1 /(4 \pi a t)^{3 / 2} \cdot \exp \left[\mathrm{x}^{2}+\mathrm{y}^{2}+\mathrm{z}^{2} /\right] 4 a t ; a$ is the thermal diffusivity $a=k / \rho c ; \rho$ and $c$ are the density and specific heat, respectively; $k$ is the thermal conductivity; and $\tau$ is the time of heat source application. Despite the use of all these arguable assumptions, Rosenthal's derivation and the resultant analytic solution have been widely accepted by the welding community although its actual applicability is still subject to verification for the specific applications.

Further, for distributive heat source, the analytic solution has been enabled by the use of a single-ellipsoidal static heat source

$$
S(x, y, z)=\frac{6 \sqrt{3} \cdot \gamma \cdot V \cdot I}{a_{h} b_{h} c_{h} \pi \sqrt{\pi}} \cdot \exp \left(-\frac{3 x^{2}}{c_{h}^{2}}-\frac{3 y^{2}}{a_{h}^{2}}-\frac{3 z^{2}}{b_{h}^{2}}\right)
$$

proposed by Goldak (Ref. 34) as illustrated in Fig. 1, where $\gamma$ is the effective heat-input coefficient that is chosen as $100 \%$ in this study because the results will be calibrated after calculation; $V$ and $I$ are welding voltage and welding current, respectively; and $a_{h}, b_{h}, c_{h}$, are the single-ellipsoidal heat source parameters.

The temperature distribution under a distributive heat source can be obtained by convoluting the point heat source solution (Equation 1) with the heat distribution (Equation 2) to superposition spatially. After simplification, the following analytic solution for the temperature distribution can be obtained (Ref. 35):

$$
\begin{gathered}
T(x, y, z) t=t_{f}=S(x, y, z) * G(x, y, z) t_{f} \\
=\frac{3 \sqrt{3} P}{\rho c \pi \sqrt{\pi}} \cdot \int_{0}^{t_{f}} \frac{1}{\sqrt{12 a\left(t_{f}-\tau\right)+a_{h}^{2}} \sqrt{12 a\left(t_{f}-\tau\right)+b_{h}^{2}} \sqrt{12 a\left(t_{f}-\tau\right)+c_{h}^{2}}} \\
\cdot \exp \left(-\frac{3 x^{2}}{12 a\left(t_{f}-\tau\right)+c_{h}^{2}}-\frac{3 y^{2}}{12 a\left(t_{f}-\tau\right)+a_{h}^{2}}-\frac{3 z^{2}}{12 a\left(t_{f}-\tau\right)+b_{h}^{2}}\right) d \tau \\
=\int_{0}^{t_{f}} P \cdot f_{x, y, z}\left(t_{f}-\tau\right) d \tau
\end{gathered}
$$

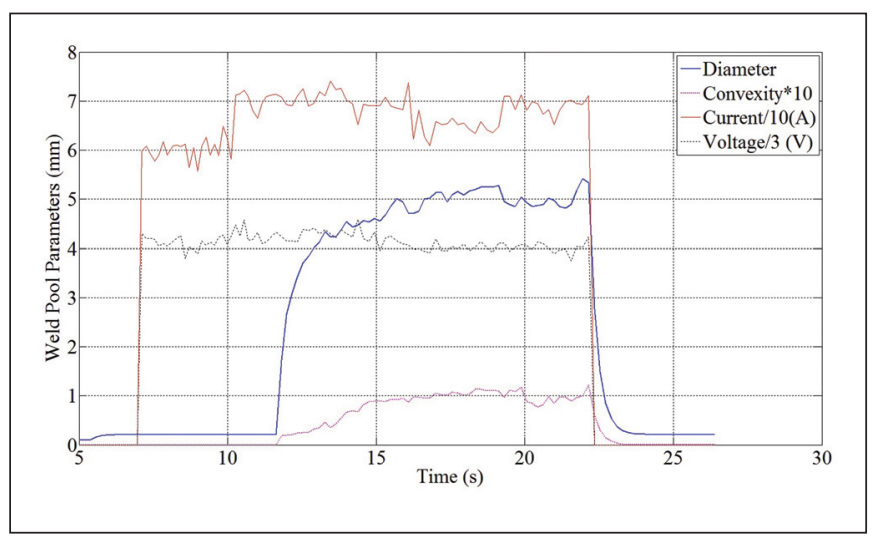

Fig. 4-Measured diameter and convexity of the weld pool surface from the verification experiment.

where $\mathrm{P}=\gamma \cdot V \cdot I$ is the power of the effective heat input from the arc and

$$
\begin{array}{r}
f_{x, y, z}(t-\tau)=\frac{3 \sqrt{3}}{\rho c \pi \sqrt{\pi} \sqrt{12 a(t-\tau)+a_{h}^{2}} \sqrt{12 a(t-\tau)+b_{h}^{2}} \sqrt{12 a(t-\tau)+c_{h}^{2}}} \\
\cdot \exp \left(-\frac{3 x^{2}}{12 a(t-\tau)+c_{h}^{2}}-\frac{3 y^{2}}{12 a(t-\tau)+a_{h}^{2}}-\frac{3 z^{2}}{12 a(t-\tau)+b_{h}^{2}}\right)
\end{array}
$$

Equation 3 is for the temperature distribution in the workpiece from a uniform initial room temperature under the application of a constant distributive power source. However, for real-time control applications, the authors target at the current $I(\tau)$ (thus $P(\tau)$ ) is adjusted according to the feedback form the in-situ penetration depth in realtime. Equation 3 is thus not, at least not directly, applicable. Hence, deriving an analytic model that can suit for a varied current/arc power that changes its value at a discrete time is necessary for future optimization of the welding process.

\section{Analytic Model with Varied Current}

The superposition principle has been applied in obtaining Equations 1 and 3. Since the superposition principle is independent from the input and the spatial convolution is independent of time, the following solution under the varying current/arc power can be directly obtained:

$$
T(x, y, z)_{t=t_{f}}=\int_{0}^{t_{f}} P(\tau) \cdot f_{x, y, z}\left(t_{f}-\tau\right) d \tau
$$

To obtain the desirable recursive solution, consider $t_{f}=t_{k}$ $+\Delta t$ the next time temperature distribution is computed. As such, the present time $t_{k}$ is $\Delta t$ earlier than $t_{f}=t_{k}+\Delta t$ and we wish to correlate the temperature distribution at $t_{f}=t_{k}+\Delta t$ to its history (temperature distribution) at $t_{k}$ and the newly applied power $P_{t_{k}}$ during $\left[\left(t_{k}, t_{k}+\Delta t\right)\right]$. Hence, the following derivation is made: 

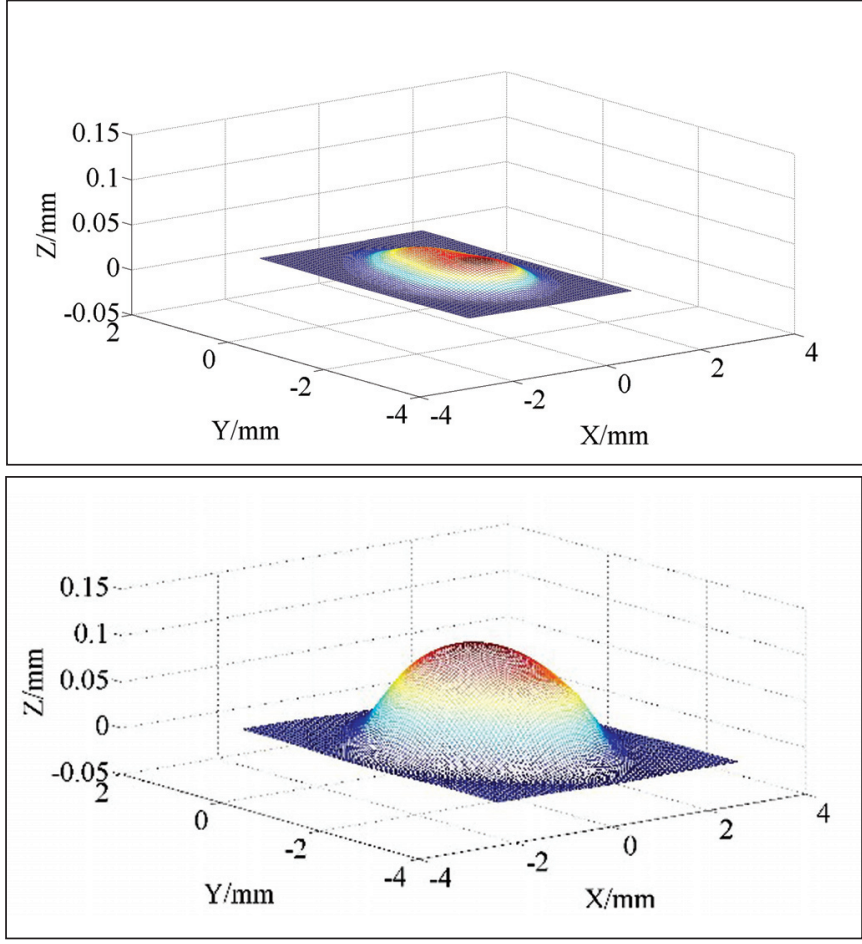
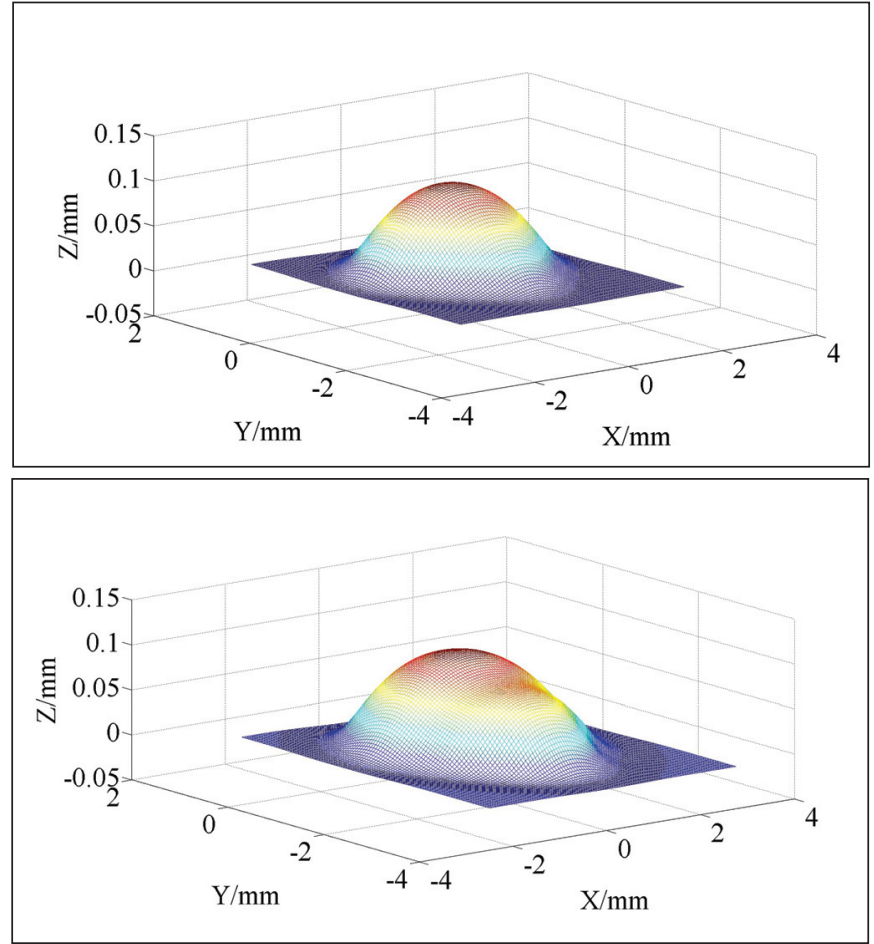

Fig. 5-Reconstructed 3D weld pool surfaces during the verification experiment.

$T(x, y, z)_{t_{k}+\Delta t}=\int_{0}^{t_{k}+\Delta t} P(\tau) \cdot f_{x, y, z}\left(t_{k}+\Delta t-\tau\right) d \tau$

arc energy during $\left(t_{k}, t_{k+1}\right)$. To see the nature of the first term, let's examine the spatial convolution of the earlier temperature distribution $T(x, y, z) t_{k}$ and $g(x, y, z)_{\Delta t}$ :

$$
\begin{aligned}
& T(x, y, z)_{t_{k}} * g(x, y, z)_{\Delta t}=\left\{\int_{0}^{t_{k}} Q(\tau) \cdot f_{x, y, z}\left(t_{k}-\tau\right) d \tau\right\} \\
& *\left\{\frac{1}{(4 \pi a \Delta t)^{3 / 2}} \cdot \exp \frac{x^{2}+y^{2}+z^{2}}{4 a \Delta t}\right\}
\end{aligned}
$$

$=\int_{0}^{t_{k}} P(\tau) \cdot f_{x, y, z}\left(t_{k}+\Delta t-\tau\right) d \tau+\int_{0}^{\Delta t} P_{t_{k}} \cdot f_{x, y, z}(\Delta t-\tau) d \tau$

where $P t_{k}=\gamma \cdot V t_{k} \cdot I t_{k}$ is the effective power of the arc in $\left(t_{k}\right.$, $\left.t_{k}+\Delta t\right)$. Since the current is not adjusted between two sampling instants, the arc power in the time interval $\left(t_{k}, t_{k}+\Delta t\right)$ is constant, as determined by the control algorithm at the sampling time $t_{k}$, and is thus denoted by subscript $t_{k}$.

To understand the implication of decomposition (4), let's examine the second term first:

$$
\begin{aligned}
\int_{0}^{\Delta t} P_{t_{k}} \cdot f_{x, y, z}(\Delta t-\tau) d \tau & =\left\{P_{t_{k}} \Delta t\right\} \int_{0}^{\Delta t}\left\{f_{x, y, z}(\Delta t-\tau) / \Delta t\right\} d \tau \\
& =B_{x, y, z} Q_{t_{k}}
\end{aligned}
$$

$\cdot \exp \left(-\frac{3 u^{2}}{12 a\left(t_{k}-\tau\right)+c_{h}^{2}}-\frac{3 v^{2}}{12 a\left(t_{k}-\tau\right)+a_{h}^{2}}-\frac{3 w^{2}}{12 a\left(t_{k}-\tau\right)+b_{h}^{2}}\right)$

$\frac{1}{(4 \pi a \Delta t)^{3 / 2}} \cdot \exp \left(-\frac{(x-u)^{2}+(y-v)^{2}+(z-w)^{2}}{4 a \Delta t}\right) d u d v d w d \tau$

By using the Gaussian integral, the above equation can be simplified as follows:

$T(x, y, z) t_{k} * g(x, y, z)_{\Delta t}$

where $B_{x, y, z}=\int_{0} \Delta t\left\{f_{x, y, z}(\Delta \mathrm{t}-\tau) / \Delta \mathrm{t}\right\} d \tau$ is a constant, when $\Delta t$ is fixed, for a given point $(x, y, z)$ and $Q t_{k}$ is the newly applied 

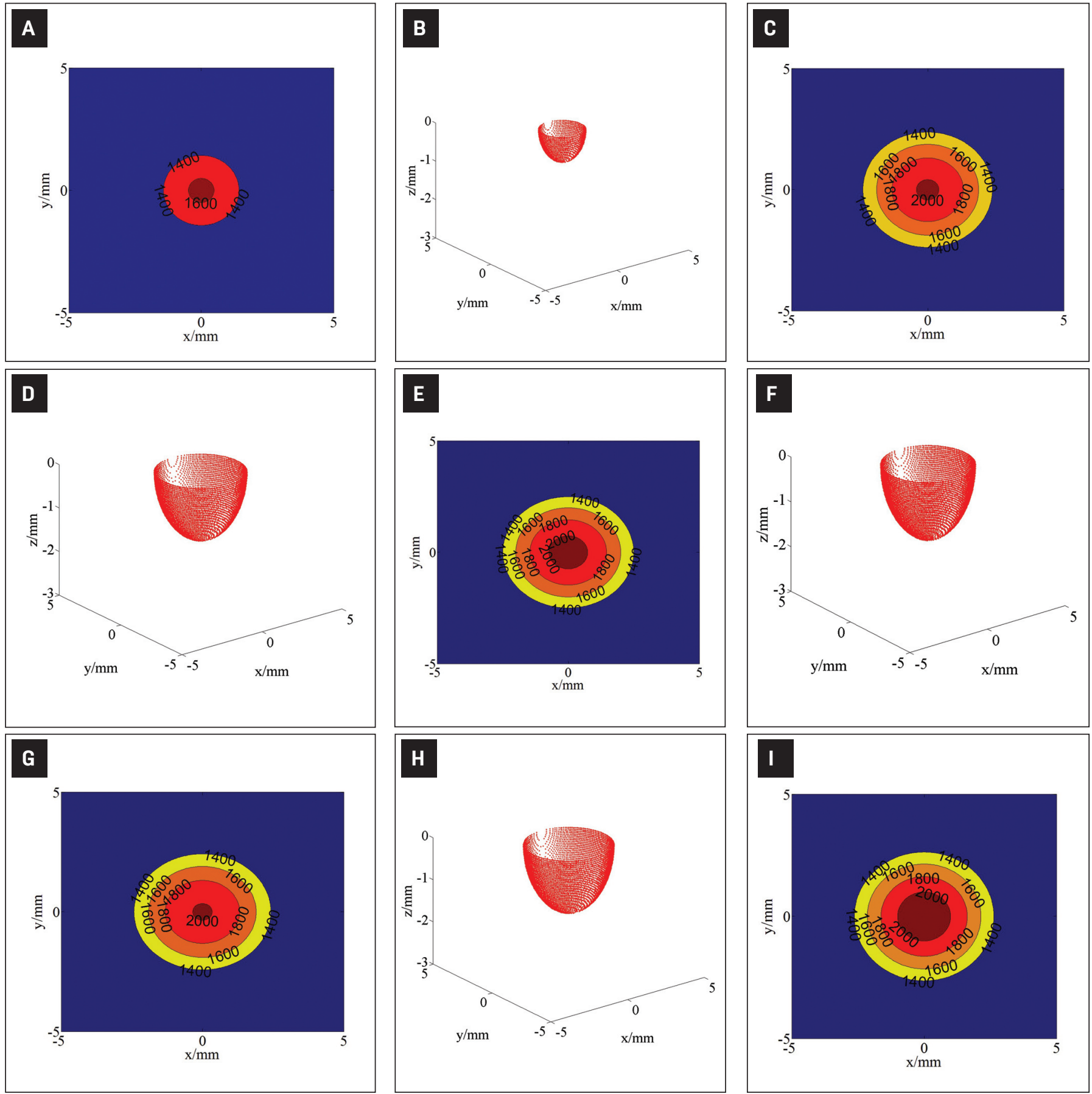

\section{J}

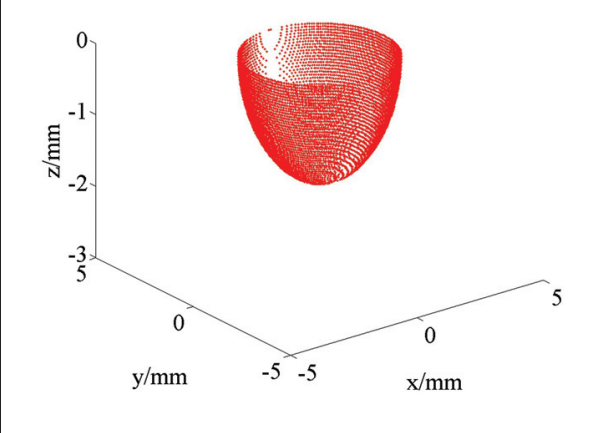

Fig. 6 - Weld pools computed using the recursive analytic model under verification experimental conditions. $A$ - Surface temperature field $\left({ }^{\circ} \mathrm{C}\right) t_{c}=3 \mathrm{~s} ; \mathrm{B}-$ whole boundary $t_{c}=3 \mathrm{~s} ; \mathrm{C}$ - surface temperature field $\left({ }^{\circ} \mathrm{C}\right) t_{c}=6 \mathrm{~s} ; \mathrm{D}$ - whole boundary $t_{c}=6 \mathrm{~s} ; \mathrm{E}$ - surface temperature field $\left({ }^{\circ} \mathrm{C}\right) t_{c}=9 \mathrm{~s} ; \mathrm{F}-$ whole boundary $t_{c}=9 \mathrm{~s} ; \mathrm{G}$ - surface temperature field $\left({ }^{\circ} \mathrm{C}\right) t_{c}=12 \mathrm{~s} ; \mathrm{H}$ - whole boundary $t_{c}=12 \mathrm{~s} ; \mathrm{I}$ - suface temperature field $\left({ }^{\circ} \mathrm{C}\right) t_{c}=15 \mathrm{~s} ; J-$ whole boundary $t_{c}=15 \mathrm{~s}$ 
Table 1 - Welding Experiment Parameters

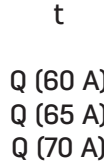

Welding Time

$15 s$

Heat input (W)

900

Heat input (W)

Heat input $(W)$

950

1000

*The arc length is $5 \mathrm{~mm}$.

Table 2 - Input Parameters for Analytic Model

\begin{tabular}{lll} 
Symbol & Quantity & Values \\
\hline$T_{0}$ & Initial temperature & $293.15 \mathrm{~K}$ \\
$\rho$ & Density & $8.03 \times 10^{-6} \mathrm{~kg} / \mathrm{mm}^{3}$ \\
$\mathrm{C}$ & Specific heat & $500 \mathrm{~J} / \mathrm{kg} \cdot \mathrm{K}$ \\
$\mathrm{k}$ & Thermal conductivity & $16.2 \times 10^{-3} \mathrm{~W} / \mathrm{mm}^{\circ} \mathrm{K}$ \\
$\mathrm{a}$ & Thermal diffusivity & $4.035 \mathrm{~mm}^{2} / \mathrm{s}$ \\
& & $4.5 \times 10^{-5} \mathrm{~K}^{-1}$ \\
$\mathrm{a}_{\mathrm{r}}(\mathrm{T})$ & Volumetric expansion coefficient & $1400^{\circ} \mathrm{C}$ \\
$\mathrm{T}_{\text {meit }}$ & Melting point & $4.153 \mathrm{~mm}$ \\
$\mathrm{a}_{\mathrm{h}}=\mathrm{b}_{\mathrm{h}}$ & Heat source parameters $(\mathrm{x}-\mathrm{y})$ & $0.511 \mathrm{~mm}$ \\
$\mathrm{C}_{\mathrm{h}}$ & Heat source parameters (depth) & \\
\hline
\end{tabular}

$=\int_{0}^{t_{k}} \frac{3 \sqrt{3} Q(\tau)}{\rho c \pi \sqrt{\pi}}$

$\frac{1}{\sqrt{12 a\left(t_{k}+\Delta t-\tau\right)+a_{h}^{2}} \sqrt{12 a\left(t_{k}+\Delta t-\tau\right)+b_{h}^{2}} \sqrt{12 a\left(t_{k}+\Delta t-\tau\right)+c_{h}^{2}}}$

$\cdot \exp \left(-\frac{3 x^{2}}{12 a\left(t_{k}+\Delta t-\tau\right)+c_{h}^{2}}-\frac{3 y^{2}}{12 a\left(t_{k}+\Delta t-\tau\right)+a_{h}^{2}}-\frac{3 z^{2}}{12 a\left(t_{k}+\Delta t-\tau\right)+b_{h}^{2}}\right) d \tau$

$=\int_{0}^{t_{k}} Q(\tau) \cdot f_{x, y, z}\left(t_{k}+\Delta t-\tau\right) d \tau=A\left(T(x, y, z)_{t_{k}}\right)$

As such, another term is indeed the contribution from the earlier temperature distribution $T(x, y, z)$ through its spatial convolution with $g(x, y, z)_{\Delta t}$. Since $g(x, y, z)_{\Delta t}$ is a given function of $(x, y, z)$ when $\Delta t$ is fixed, $A$ is a given function of the temperature history $T(x, y, z) t_{k}$. Hence,

$$
T(x, y, z) t_{k+1}=A\left(T(x, y, z) t_{k}\right)+B_{x, y, z} Q t_{k}
$$

with the first term as a function of the earlier temperature distribution and second term as a function of newly applied arc energy. Both functions also depend on $\Delta t$ used, but would only be $(x, y, z)$ dependent when $\Delta t$ is fixed.

\section{Computation}

While the computation for $B_{x, y, z}=\int_{0} \Delta t\left\{f_{x, y, z}(\Delta t-\tau) / \Delta t\right\} d \tau$ using a numerical method is straightforward and can be comput- ed for each $(x, y, z)$ of interest in advance, the computation of $A\left(T(x, y, z) t_{k}\right)$ requires the knowledge of the varying $T(x, y, z) t_{k}$, which is not available in advance. As a result, $A\left(T(x, y, z) t_{k}\right)$ must be computed in real-time each time. This is a challenging task because $A\left(T(x, y, z) t_{k}\right)$ must be computed as the convolution of the calibrated $\left.T(x, y, z) t_{k}\right)$, rather than the previously computed $g(x, y, z)_{\Delta t}$, and the calibrated $\left.T(x, y, z) t_{k}\right)$ will be given as a large set of data at discrete points. Computing the three-dimensional spatial convolution using a numerical computation is not feasible for real-time applications.

To overcome this difficulty, one may consider fitting $T(x, y, z) t_{k}$ into an analytic description whose convolution can be solved analytically. To this end, the following description is proposed for the temperature distribution:

$$
T(x, y, z)_{t_{k}}=T_{\text {top }} \cdot \exp \left(-\frac{x^{2}}{K_{k_{1}}^{2}}-\frac{y^{2}}{K_{k_{2}}^{2}}-\frac{z^{2}}{K_{k_{3}}^{2}}\right)
$$

where $T_{\text {top }}$ is an adjustable scale and $\left(K k_{1}, K k_{2}, K k_{3}\right)$ are the shape parameters. This description is proposed because $T_{\text {top }}$ can represent the peak temperature at the arc, and the decreases in the temperature away from the center in the different directions can be described similarly as the heat source distribution. For identification purpose, this nonlinear model may be easily transformed into a linear equation

$$
\operatorname{Ln}\left(T(x, y, z)_{t_{k}}\right)=\operatorname{Ln}\left(T_{\text {top }}\right)-\frac{x^{2}}{K_{k_{1}}^{2}}-\frac{y^{2}}{K_{k_{2}}^{2}}-\frac{z^{2}}{K_{k_{3}}^{2}}
$$

such that the linear least square estimate of $\left(\operatorname{Ln}\left(T_{\text {top }}\right)\right.$, $\left.-1 / K^{2}{ }_{k 1}-1 / K^{2}{ }_{k 2},-1 / K_{k 3}^{2}\right)^{\mathrm{T}}$ can be obtained analytically to 


\section{A}

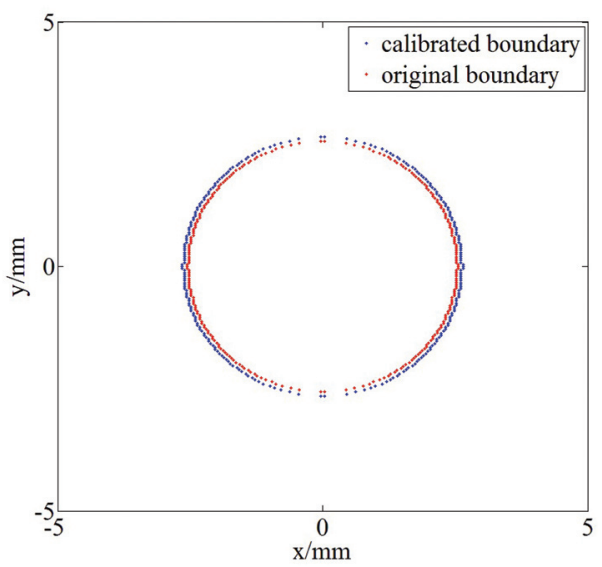

B

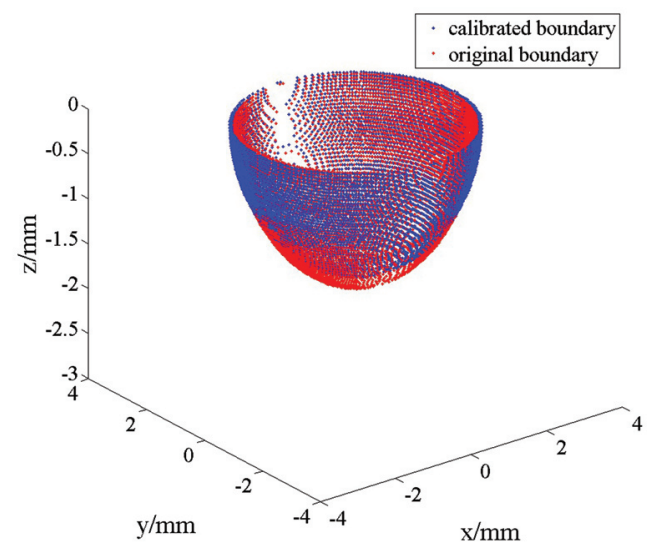

Fig. 7-Results of the weld pool calibration. A - The calculated and calibrated weld pool surfaces; B - the calculated and calibrated whole points.

calculate $\left(T_{\text {top }}, K_{k 1}^{2}, K_{k 2}^{2}, K_{k 3}^{2}\right)^{T}$. (For stationary welding where $K^{2}{ }_{k 1}=K_{k 2}^{2}$, the parameters can also be identified.) As such, $T_{\text {top }} \cdot \exp \left(-x^{2} / K_{k 1}^{2}-y^{2} / K_{k 2}^{2}-z^{2} / K_{k 3}\right)^{2}$ becomes the analytic description of the earlier temperature distribution. Its convolution with $g(x, y, z)_{\Delta t}$ is

$$
\begin{aligned}
& A\left(T(x, y, z)_{t_{k}}\right)=\frac{1}{(4 \pi a \Delta t)^{3 / 2}} \int_{-\infty}^{+\infty} \int_{-\infty}^{+\infty} \int_{-\infty}^{+\infty} T_{t o t} \\
& \cdot \exp \left(-\frac{u^{2}}{K_{k_{1}}^{2}}-\frac{v^{2}}{K_{k_{2}}^{2}}-\frac{w^{2}}{K_{k_{3}}^{2}}\right) \\
& \cdot \exp \left(-\frac{\left((x-u)^{2}+(y-v)^{2}+(z-w)^{2}\right)}{4 a \Delta t}\right) d u d v d w
\end{aligned}
$$

Subsequently, by evaluating and simplifying,

$$
\begin{aligned}
& A\left(T(x, y, z)_{t_{k}}\right)=T_{\text {top }} \cdot \sqrt{\frac{K_{k_{1}}^{2}}{4 a \Delta t+K_{k_{1}}^{2}}} \sqrt{\frac{K_{k_{2}}^{2}}{4 a \Delta t+K_{k_{2}}^{2}}} \sqrt{\frac{K_{k_{3}}^{2}}{4 a \Delta t+K_{k_{3}}^{2}}} \\
& \exp \left(-\frac{x^{2}}{4 a \Delta t+K_{k_{1}}^{2}}-\frac{y^{2}}{4 a \Delta t+K_{k_{2}}^{2}}-\frac{z^{2}}{4 a \Delta t+K_{k_{3}}^{2}}\right)
\end{aligned}
$$

Hence, the transient temperature distribution can by recursively calucated when the welding current is varied.

\section{Summary of the Recursive Analytic Model Calibrated by Measurements}

In summary, the resultant analytic model that recursively

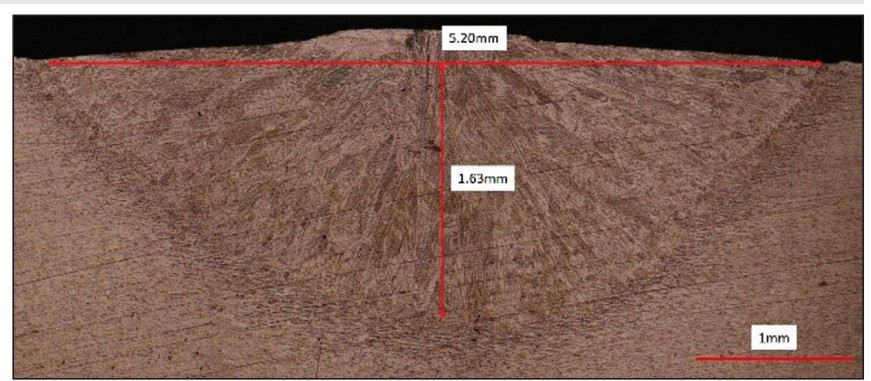

Fig. 8 - Cross section of the weld from the verification experiment.

computes the temperature distribution is given by Equation 4. The two terms in Equation 4 are given by Equations 5 and 11, respectively. Further, Equation 11 requires parameters in the analytic description of the temperature distribution of Equation 8. These parameters are obtained by fitting the analytic description of Equation 8 to the set of points that represent the earlier temperature distribution. The resultant analytic model is then calibrated by the measured 3D weld pool surface. The calibrated temperature distribution then provides the set of points to represent the "earlier temperature distribution" for the next time.

\section{Experimental Procedure}

The measurement of the weld pool surface to be used for calibration is obtained from an in-situ 3D weld pool surface sensor developed at the University of Kentucky (Refs. 36, 37) as shown in Fig. 2. In this system, a 20-mW power illumination laser with a 660 -nm wavelength is used to project a $19 \times$ 19 dot matrix structured light pattern on the weld pool surface. The mirror-like weld pool surface reflects the incident dots following the law of reflection. The reflected dots are captured by the imaging plane placed approximately 2 in. away from the torch. The arc light is also reflected and captured by the imaging plane, however, because its optic attenuation performance is obvious when the distance is increased, the reflected dots can be obtained by image processing from the pictures captured by a CCD camera. By using a specific image pro- 


\section{A}

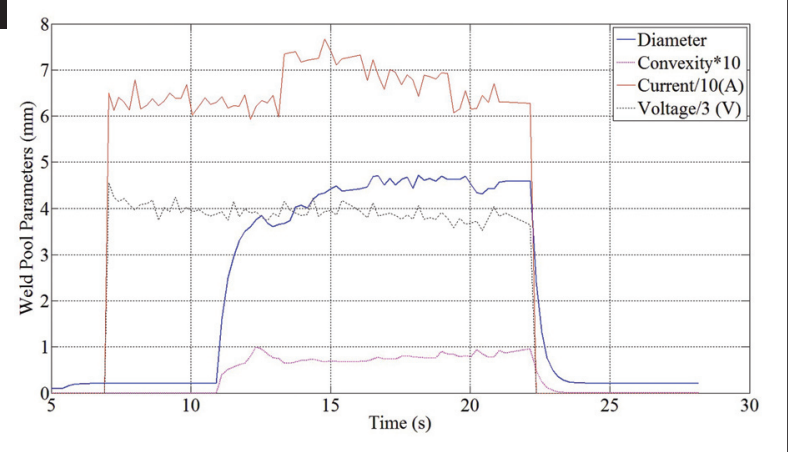

B

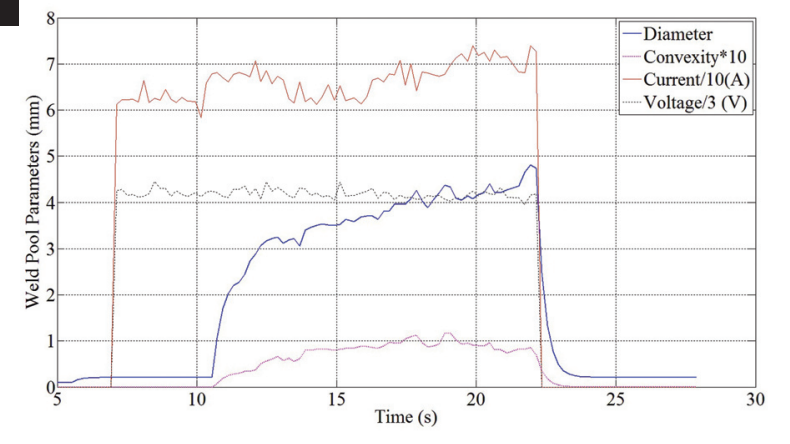

Fig. 9-Measured diameter and convexity during additional verification experiments. A - 60-60-70-65-60 A; B 60-65-60-65-70 A.
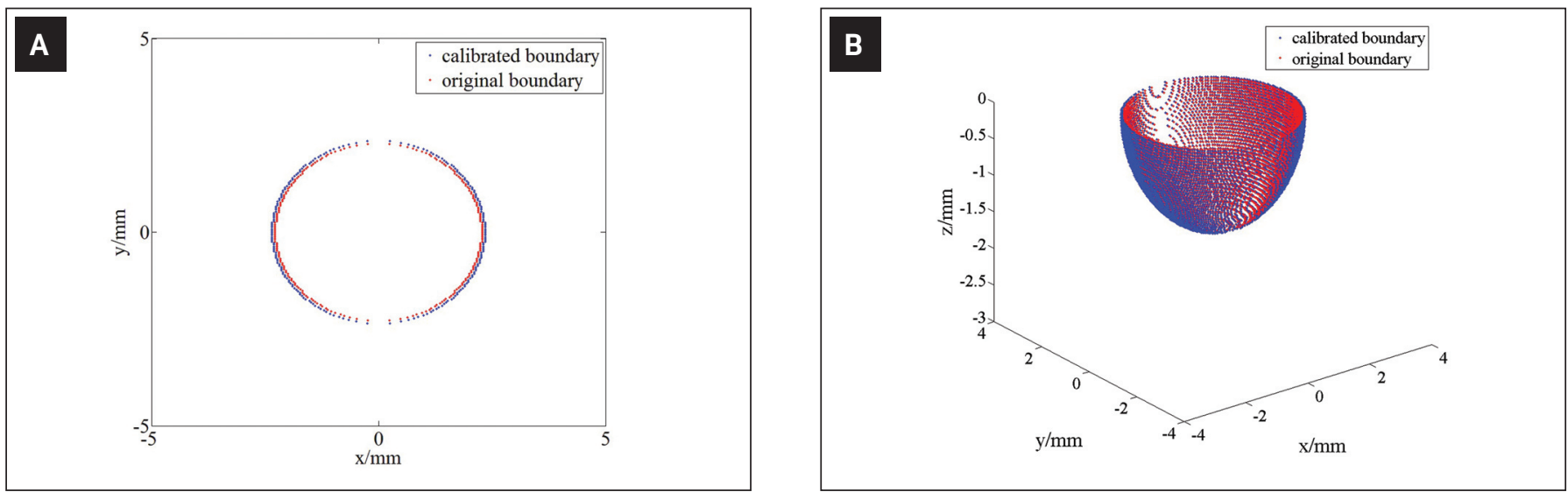

\section{C}

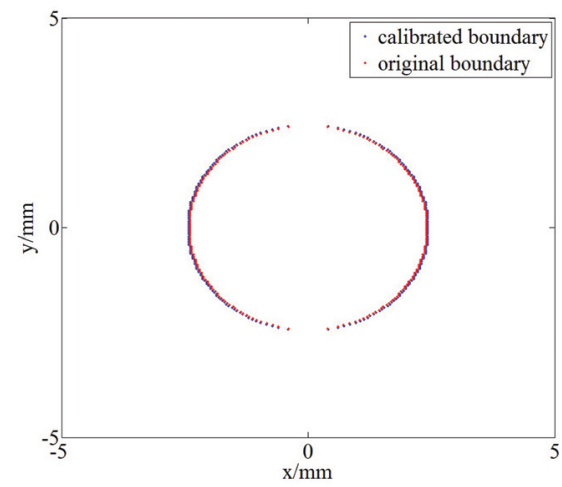

D

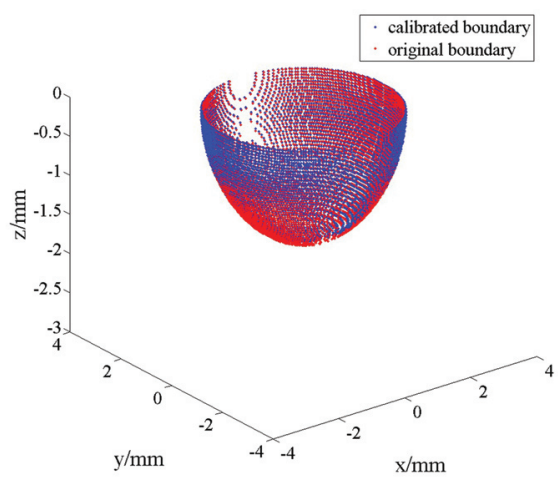

Fig. 10 - Calibration results in the additional verification experiments. A - The calculated and calibrated weld pool surfaces: a; $B$ - the calculated and calibrated whole points: a; C - the calculated and calibrated weld pool surfaces: b; D - the calculated and calibrated whole points: $b$.

cessing and reconstruction algorithm (Ref. 38), a 3D weld pool surface can be obtained in real time.

Because the 3D weld pool surface shape (radius and convexity) is reconstructed in real-time, the elevation volume needed for calibration is calculated by the following equation,

$$
\Delta V_{m}=A_{x o y} \cdot H
$$

where $\Delta V_{m}$ is the elevated volume from the measured weld pool surface, $A_{\text {xoy }}$ is the area of the weld pool surface in face $X O Y$, and $H$ is the average elevation of the weld pool surface.
The average elevation above the workpiece surface is computed by averaging all the points inside the weld pool boundary including interpolated and original points, which are more than 200 points in that area.

With the available measurement of the 3D weld pool surface, the temperature distribution computed from the recursive solution can be calibrated similarly to the previous analytic model under constant current (Ref. 1). That is, first shrink/expand the recursively computed temperature distribution $T(x, y, z)$ in $x-y$ directions such that $T\left(\lambda_{x y}{ }^{*} x, \lambda_{x y}{ }^{*} y, z\right)$ matches the weld pool radius with that from the measured 

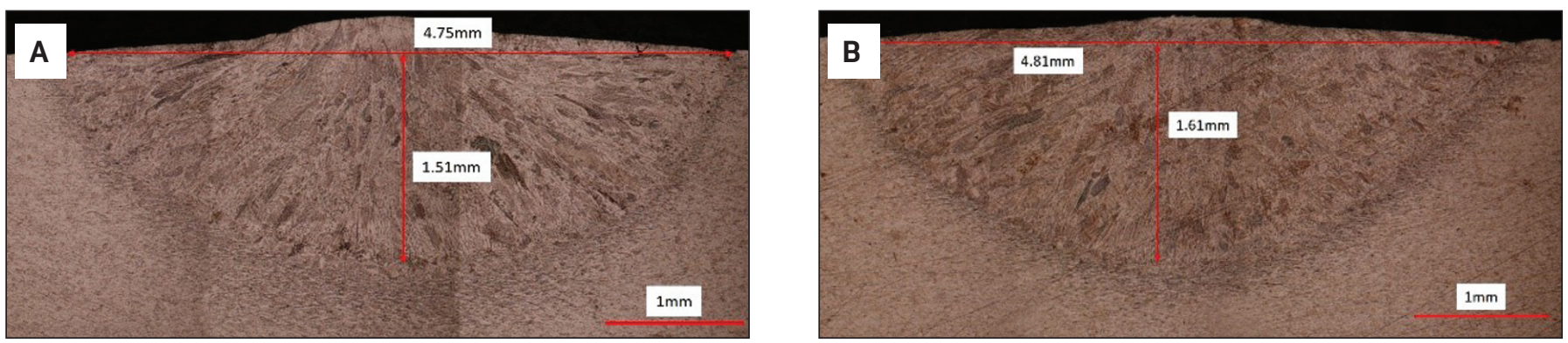

Fig. $11-$ Cross sections of the welds from the additional verification experiements. $A-C a s e: a ; B-$ case: $b$.

weld pool. The calibration is then done in depth direction such that $T\left(\lambda_{x y}{ }^{*} \mathrm{x}, \lambda_{x y}{ }^{*} \mathrm{y}, \lambda_{z}{ }^{*} z\right)$ matches the weld pool surface elevation volume with that from the measurement of the $3 \mathrm{D}$ weld pool surface.

To verify the recursive analytic model, a varying current is needed. To this end, the current waveform shown in Fig. 3 is used in which the current changes randomly every $3 \mathrm{~s}$ in $15 \mathrm{~s}$ of the total welding time among 60,65 , and $70 \mathrm{~A}$.

Verification of stationary bead-on-plate GTAW experiments was performed on 3-mm-thick Type 304 stainless steel plates. The dimension of the workpiece is $300 \times 100$ $\mathrm{mm}$. The experimental welding parameters are given in Table 1 . The heat input distribution parameters $a_{h}, b_{h}, c_{h}$ needed in the analytic model are given in Table 2 as determined from Ref. 2. Other input parameters needed for the analytic model are also given in Table 2.

\section{Verification and Analysis}

\section{Experimental Results for Calibration}

The weld pool diameter and convexity are calculated from real-time reflected images monitored by the measurement system. The convexity was previously defined (Ref. 39) as the average elevation of the weld pool surface above the workpiece surface longitudinally along the weld joint. In this work, the entire volume of the surface elevation above the workpiece surface is divided by the surface area that is used to define another convexity. To avoid confusion, it can be referred to as the aerial convexity while the previously defined one can be considered as a linear convexity. Unless otherwise specified, the convexity in this study is the aerialconvection.

Experimental results are shown in Fig. 4, which indicated the process started at measured time $t_{m}=7.2 \mathrm{~s}$ and finished at $\mathrm{t}_{\mathrm{m}}=22.1 \mathrm{~s}$ for a total arc-on time of $15 \mathrm{~s}$, as equal to calculation time $t_{c}=0 \mathrm{~s}$ and $t_{c}=15 \mathrm{~s}$. The current began at $60 \mathrm{~A}$ and changed every $3 \mathrm{~s}$ among 60,65 , and $70 \mathrm{~A}$. The actual current shown in Fig. 4 fluctuated slightly from the programmed value. The measurement system obtained and calculated a pair of diameter, and convexity every $180 \mathrm{~ms}$. In the first few seconds (from approximately $t_{m}=7 \mathrm{~s}$ to $t_{m}=12 \mathrm{~s}$ ), there was no diame- ter or convexity calculated because the weld pool was not established or was too small. Then the diameter and convexity increased rapidly (from approximately $t_{m}=12 \mathrm{~s}$ to $t_{m}=15 \mathrm{~s}$ ). Then the increases were slowed (approximately $t_{m}=15 \mathrm{~s}$ to $t_{m}=$ $19 \mathrm{~s}$ ). The slight decreases then occurred (approximately $\mathrm{t}_{\mathrm{m}}=$ $19 \mathrm{~s}$ to $t_{m}=21.5 \mathrm{~s}$ for the diameter and $t_{m}=20 \mathrm{~s}$ to $t_{m}=21 \mathrm{~s}$ for the convexity) due to the decrease in the current $\left(t_{m}=16 \mathrm{~s}\right.$ to $t_{m}=19 \mathrm{~s}$ ) and the response delay. With the current being increased again (approximately $t_{m}=19 \mathrm{~s}$ to $t_{m}=22 \mathrm{~s}$ ), the diameter and convexity of the weld pool increased back to 5.3 and $0.12 \mathrm{~mm}$ at the end of the process.

A set of reconstructed 3D weld pool surfaces are shown in Fig. 5. As shown, the weld pool increased rapidly/clearly in the first $3 \mathrm{~s}$ and then the increased speed reduced. Table 3 summarizes the measurements of the weld pool surface near the end of welding, i.e., at $t_{m}=22.1 \mathrm{~s}$. One should note, although the central area has relatively high elevation, the convexity of the entire weld pool is relatively small. That is, for circular bands with the same radius interval, the area increases rapidly as the radius (distance from the $\mathrm{z}$-axis) increases. As such, the majority of the elevated surface is at relatively low elevations.

\section{Analytic Model and Calibration}

The analytic model calculates the distribution of weld pool temperature distribution in real time. Because the current is changed every $3 \mathrm{~s}$, the parameters as $T_{\text {top }}, K k_{1}=K k_{2}$ and $K k_{3}$ in the analytic description of the temperature distribution should also been determined every $3 \mathrm{~s}$. The resultant $K k_{1}=K k_{2}$ and $K k_{3}$ are shown in Table 4, especially at $\mathrm{t}_{\mathrm{c}}=0 \mathrm{~s}, K_{k_{1}}=K_{k_{2}}=$ $K_{k_{3}}=\infty$ and $T_{\text {top }}=298 \mathrm{~K}$. Then the temperature distribution at $\mathrm{t}_{\mathrm{c}}=3 \mathrm{~s}$ is calculated using the initial temperature distribution as the earlier temperature distribution history and the newly applied arc power. To prepare for the next computation at $t_{c}=$ $6 \mathrm{~s}$, the obtained temperature distribution at $\mathrm{t}_{\mathrm{c}}=3 \mathrm{~s}$ is used to fit the analytic description Equation 8 via Equation 9. The resultant parameters are $K k_{1}=K k_{2}=4.5475 \mathrm{~mm}$ and $K_{3}=3.4722$ $\mathrm{mm}$ with a MSE (mean square error) $\epsilon=\left(T(x, y, z) t_{k}-\mathrm{T}_{\text {ori }}(x, y\right.$, $\left.z) t_{k}\right) / T_{\text {ori }}(x, y, z) t_{k}$ of 0.0698 . Repeating this process, the final temperature distribution at $t_{c}=15 \mathrm{~s}$ can be obtained.

Figure 6 shows the computed temperature distribution

Table 3-Results of Measured Weld Pool Near the End of the Verification Experiment 
and weld pool boundary series. As shown, the temperature distribution continually increased first in $t_{c}=0 \mathrm{~s}$ to $t_{c}=9 \mathrm{~s}$, then decreased a little during $t_{c}=12$ s to $t_{c}=15 \mathrm{~s}$ caused by the decrease in the current, and then increased again. It can be seen more clearly from the boundary that both the weld pool surface and depth reduced during $t_{c}=12 \mathrm{~s}$ to $t_{c}=15 \mathrm{~s}$ indicating that the weld pool was solidifying a little as the current decreased. When the current increased again, the weld pool enlarged again.

The calibration is conducted by matching the measured and computed radius and elevation volume to obtain an accurate depth of penetration and can be done for each of the recursively computed temperature distribution. However, because the depth of penetration can only be measured at the end of the process as $t_{c}=15 \mathrm{~s}$ by cross section, the verification can only be done using the temperature distribution calibrated at $t_{c}=15 \mathrm{~s}$. As such, only the calibration for the last temperature distribution is shown in Fig. 6.

To calibrate, the calculated and measured radius are matched first to calibrate in the $x-y$ directions. The calculated radius is $2.56 \mathrm{~mm}$, and the measured radius is $2.65 \mathrm{~mm}$. Hence, the calibration ratio in the $\mathrm{x}-\mathrm{y}$ direction is $\lambda_{\mathrm{xy}} *=$ $2.65 / 2.56=1.0352$. The analytic model after the calibration in $\mathrm{x}-\mathrm{y}$ directions is

$$
T_{c-x y}(x, y, z)=T(1.0352 x, 1.0352 y, z)
$$

Figure 7A shows the weld pool boundary before and after the calibration in $x-y$ directions. A difference between $T_{c-x y}$ $(x, y, z)$ computed and measured elevation volumes will trigger the calibration in the depth direction. The elevation volume computed using the original analytic model before calibration is $0.5746 \mathrm{~mm}^{3}$. After the calibration in $\mathrm{x}-\mathrm{y}$ directions, this volume increases to $0.6157 \mathrm{~mm}^{3}$, a little larger than the measurement $0.5667 \mathrm{~mm}^{3}$. The calibration in the depth direction is thus needed. It is found that for $\lambda_{z}=$ 0.9204 , the elevation volume computed from $T(1.0352 x$, $1.0352 y, \lambda_{z} z$ ) equals $0.5667 \mathrm{~mm}^{3}$. As such, $\lambda_{z}{ }^{*}=0.9204$ and the finally calibrated analytic solution is

$$
T_{c}(x, y, z)=T(1.0352 x, 1.0352 y, 0.9204 z)_{t=15 s}
$$

where $\mathrm{T}(x, y, z)_{\mathrm{t}=15 \mathrm{~s}}$ is the temperature distribution at $\mathrm{t}=15$ $s$ calculated from the recursive analytic model.

Using this calibrated model, the final shape of the weld pool can be computed. Its comparison with that computed from the original analytic model is shown in Fig. 7B. The depth of the weld pool when the welding ends as computed using the calibrated model is $1.6208 \mathrm{~mm}$, changed from $1.761 \mathrm{~mm}$ computed from the original analytic model.

\section{Verification}

The calibrated model can be verified by comparing between the estimated depth of the weld penetration with that measured from the cross section. As shown in Fig. 8, the cross section shows $1.63 \mathrm{~mm}$ for the depth of weld penetration and $5.20 \mathrm{~mm}$ for the weld width/diameter. The results from the calibrated model are 1.6208 and $5.3 \mathrm{~mm}$, respectively. The accuracies appear to be adequate for typical precision joining applications.

\section{Additional Experimental Verifications}

Additional experiments with different current waveforms were conducted to further verify the proposed recursive analytic model. The current was also changed every $3 \mathrm{~s}$ within $15 \mathrm{~s}$ of total welding time. In additional experiment $a$, the current was 60-60-70-65-60 A, while for additional experiment $b$, the current was 60-65-60-65-70 A. The actual current waveforms and measured diameters and convexities are plotted in Fig. 9. Both of the currents were a little higher than the setting values but still acceptable. The voltages were around $12 \mathrm{~V}$. For additional experiment $a$, the diameter and convexity finished at 4.7 and $0.099 \mathrm{~mm}$, respectively, at the end; however, because the current begins decreasing at $t_{m}=16.3 \mathrm{~s}$, the maximum penetration depth should also be acquired at the same time, the diameter and convexity measured at 4.72 and $0.082 \mathrm{~mm}$. For additional experiment $b$, they finished at 4.85 and $0.09 \mathrm{~mm}$ at the end. The elevation volume can be calculated according to the measurement results as $0.3693 \mathrm{~mm}^{3}$ at $t_{\mathrm{m}}=16.3 \mathrm{~s}$ for additional experiment $a$, and $0.4358 \mathrm{~mm}^{3}$ for additional experiment $b$.

The calculation results are shown in Table 5. For additional experiment $a$, the maximal penetration depth occured at $9 \mathrm{~s}$. At this time, the diameter and evaluation volume calculated by the model before calibration were 4.64 nd 0.3708 $\mathrm{mm}^{3}$, respectively. For additional experiment $b$, the maximal penetration depth occured at 9 s finished at the end, with 4.8 $\mathrm{mm}$ diameter and $0.4415 \mathrm{~mm}^{3}$ evaluation volume, respectively. The fitting parameters for all the "earlier" temperature distributions and their fitting MSE are also shown in Table 5. All the MSEs are around 0.06, showing that the analytic description of the temperature distribution fits the discrete points of temperatures well.

For additional verification experiment $a$, the radius was calibrated from $2.32 \mathrm{~mm}$ calculated by the original analytic model to $2.35 \mathrm{~m}$; for additional verification experiment $b$, it was calibrated from 2.40 to $2.425 \mathrm{~m}$. The calibration ratio in $\mathrm{x}-\mathrm{y}$ directions is thus $\lambda_{x y}{ }^{*}=2.35 / 2.32=1.0129$ and $\lambda_{x y}{ }^{*}=$ $2.425 / 2.40=1.0104$, respectively. Figure $10 \mathrm{~A}$ and $\mathrm{C}$ show

\begin{tabular}{|c|c|c|c|c|c|}
\hline Time $t_{c}(s)$ & $\kappa_{\mathrm{kl}}=\kappa_{\mathrm{k} 2}(\mathrm{~mm})$ & $\kappa_{k 3}(\mathrm{~mm})$ & Radius (mm) & Elevation Volume $\left(\mathrm{mm}^{3}\right)$ & MSE \\
\hline 3 & 4.5475 & 3.4722 & 1.28 & 0.0271 & 0.0698 \\
\hline 6 & 5.0164 & 3.8664 & 2.28 & 0.3429 & 0.0687 \\
\hline 12 & 5.2267 & 4.0358 & 2.32 & 0.3588 & 0.0672 \\
\hline 15 & - & - & 2.56 & 0.5746 & - \\
\hline
\end{tabular}

Table 4- Results of Temperature Distribution Recursive Computation in Verification Experiment 
Table 5 - Temperature Distribution Parameters and Calculation Results for Additional Verification

Experiments

(a) 60-60-70-65-60 A

\begin{tabular}{cccccc}
\hline Time $t_{\mathrm{c}}(\mathrm{s})$ & $\kappa_{\mathrm{k} 1}=\kappa_{\mathrm{k} 2}(\mathrm{~mm})$ & $\kappa_{\mathrm{k} 3}(\mathrm{~mm})$ & Radius $(\mathrm{mm})$ & Elevation Volume $\left.(\mathrm{mm})^{3}\right)$ & MSE \\
\hline 0 & $\infty$ & $\infty$ & 0 & 0 & - \\
3 & 4.5475 & 3.4722 & 1.28 & 0.0271 & 0.0698 \\
6 & 4.9699 & 3.8263 & 1.84 & 0.1201 & 0.0692 \\
9 & 5.0626 & 3.8986 & 2.32 & 0.3708 & 0.069 \\
12 & 5.1673 & 3.9863 & 2.24 & 0.3127 & 0.0678 \\
15 & - & - & 2.08 & 0.2166
\end{tabular}

(b) 60-65-60-65-70 A

\begin{tabular}{cccccc}
\hline Time $t_{c}(\mathrm{~s})$ & $\kappa_{\mathrm{k} 1}=\kappa_{\mathrm{k} 2}(\mathrm{~mm})$ & $\kappa_{\mathrm{k} 3}(\mathrm{~mm})$ & Radius $(\mathrm{mm})$ & Elevation Volume (mm $\left.{ }^{3}\right)$ & $\mathrm{MSE}$ \\
\hline 0 & $\infty$ & $\infty$ & 0 & 0 & - \\
3 & 4.5475 & 3.4722 & 1.28 & 0.0271 & 0.0698 \\
6 & 5.0371 & 3.8843 & 2.12 & 0.2380 & 0.0684 \\
9 & 5.2114 & 4.0252 & 2.12 & 0.2268 & 0.0671 \\
12 & 5.2322 & 4.0388 & 2.32 & 0.3589 & 0.0673 \\
15 & - & - & 2.40 & 0.4415 & - \\
\hline
\end{tabular}

Table 6 - Calibration Results in Additional Verification Experiments

\begin{tabular}{cccc} 
Current (A) & $\lambda_{\text {xxy }}$ & $\lambda_{z z}$ & Model \\
\hline 65 & 1.0129 & 0.9708 & $T(1.0129 x, 1.0129 y, 0.9708 z)$ \\
60 & 1.0104 & 0.9667 & $T(1.0104 x, 1.0104 y, 0.9667 z)$ \\
\hline
\end{tabular}

the weld pool boundaries before and after the calibration in $\mathrm{x}-\mathrm{y}$ directions. After the calibration in $\mathrm{x}-\mathrm{y}$ directions, the elevation volume was increased from 0.3708 to $0.3804 \mathrm{~mm}^{3}$ and from 0.4415 to $0.4508 \mathrm{~mm}^{3}$, respectively, for $a$ and $b$. In the subsequent calibration in the depth direction, the resultant was $\lambda_{z}^{*} 0.9708$ and 0.9667 , respectively. The final calibration results are shown in Table 4 .

Using the calibration results, the weld pools were computed again. Figure 10B and D show the comparison of the weld pools before and after calibration. The penetration after the calibration became 1.5154 and $1.5864 \mathrm{~mm}$ for cases $a$ and $b$, respectively.

The accuracy of the calibrated model can be verified by comparing it with the measurement from the cross section. As shown in Fig. 11A, the penetration measured from the cross section of the weld for additional verification experiment $a$ was $1.51 \mathrm{~mm}$. It is very close to that calculated from the calibrated model, i.e., $1.5154 \mathrm{~mm}$. The error $\in=$ $(1.51-1.5154) / 1.51=0.36 \%$. From Fig. 11B, the measured penetration for additional verification experiment $b$ is 1.61 $\mathrm{mm}$. The penetration computed from the calibrated model, $1.5864 \mathrm{~mm}$, is also very close to the measured penetration. The error $\in=(1.61-1.5864) / 1.61=1.47 \%$. As such, the proposed calibration method is further considered experimentally verified for its ability to accurately predict the depth of the weld penetration for other welding currents used.

\section{Conclusions}

The objective of this work was to continuously establish the scientific foundation to monitor how deeply a developing weld pool has penetrated underneath the workpiece during GTAW as a follow-up to the authors' recent efforts on the analytic model calibrated by the 3D measurements. To address the challenge that the computation for the integration associated with the analytic model increases with time, a recursive solution was derived such that the temperature distribution can be computed from an earlier history and newly applied arc energy. As a result, the computation needed to calculate the temperature distribution does not increase/change as the welding time increases. To further reduce the computation time, an analytic description is fit for the earlier distribution as given by discrete points such that the contribution of the temperature distribution to the present temperature distribution can be analytically evaluated to minimize the needed online computation. Verification experiments confirmed the calibrated recursive analytic model predicted the measured depths of welds from cross sections accurately.

\section{Acknowledgments}

This work was funded in part by the National Science Foundation under grant NSF 1208420 and the China Scholarship Council.

\section{References}

1. Wu, S., Gao, H., Zhang, W., and Zhang, Y. M. 2017. Analytic weld pool model calibrated by measurements - Part I. Welding Journal 96(6): 193-s to 202-s.

2. Wu, S., Gao, H., Zhang, W., and Zhang, Y. M. Analytic weld pool model calibrated by measurements - Part II. (Accepted for publication.) 
3. Mnich, C. 2004. Development of a synchronized high-speed, stereovision system for in situ weld pool measurement. MS thesis, Engineering Division, Colorado School of Mines.

4. Zhao, D. B., Yi, J. Q., et al. 2003. Extraction of three-dimensional parameters for weld pool surface in pulsed GTAW with wire filler. Journal of Manufacturing Science and Engineering 125: 493-503. DOI:10.1115/1.1556400

5. Kovacevic, R., and Zhang, Y. M. 1996. Sensing free surface of arc weld pool using specular reflection: Principle and analysis. Proceedings of the Institution of Mechanical Engineers, Part B. Journal of Engineering Manufacturing 210(6): 553-564. DOI:

10.1243/PIME_PROC_1996_210_154_02

6. Zhang, Y. M., Song, H. S., and Saeed, G. 2006. Observation of a dynamic specular weld pool surface. Measurement Science and Technol ogy 17(6): L9-L12. DOI: 10.1088/0957-0233/17/6/L02

7. Song, H. S., and Zhang, Y. M. 2009. Error analysis of a three-dimensional GTA weld pool surface measurement system. Welding Journal 88(7): 141-s to 148 -s.

8. Zacksenhouse, M., and Hardt, D. 1984. Weld pool impedance identification for size measurement and control. ASME Journal of Dynamic Systems, Measurement, and Control 105(3): 179-184. DOI: 10.1115/1.3140652

9. Anedenroomer, A. J. R., and den Ouden, G. 1998. Weld pool oscillation as a tool for penetration sensing during pulsed GTA welding. Welding Journal 77(5): 181-187.

10. Hartman, D. A., DeLapp, D. R., Cook, G. E., and Barnett, R. J. 1999. Intelligent fusion control throughout varying thermal regions. Proceedings of the IEEE Industry Applications Conference. DOI: 10.1109/IAS.1999.800018

11. Yudodibroto, B., Hermans, M., Hirata, Y., and den Ouden, G. 2004. Influence of filler wire addition on weld pool oscillation during gas tungsten arc welding. Science and Technology of Welding and Joining 9(2): 163-168. DOI: 10.1179/136217104225012274

12. Hardt, D. E. 1984. Ultrasonic measurement of weld penetration. Welding Journal 63(9): 273-s to 285-s.

13. Carlson, N. M., and Johnson, J. A. 1988. Ultrasonic sensing of weld pool penetration. Welding Journal 67(11): 239-s to 246-s.

14. Mi, B., and Ume, C. 2006. Real time weld penetration depth monitoring with laser ultrasonic sensing system. Transactions of ASME: Journal of Manufacturing Science and Engineering 128(2): 280-286. DOI: $10.1115 / 1.2137747$

15. Kita, A. 2005. Measurement of weld penetration depth using non-contract ultrasound method. 2005. PhD dissertation, Georgia Institute of Technology. pp. 22-28.

16. Dixon, S., Edwards, C., and Palmer, S. 1999. A laser-EMAT system for ultrasonic weld inspection. Ultrasonics 37(4): 273-281. DOI: 10.1016/S0041-624X(99)00002-5

17. Chen, W., and Chin, B. A. 1990. Monitoring joint penetration using infrared sensing techniques. Welding Journal 69(4): 181-s to 185-s.

18. Nagarajan, S., Chin, B. A., and Chen, W. 1992. Control of the welding process using infrared aensor. IEEE Transactions on Robotics and Automation 8(1): 86-93. DOI: 10.1109/70.127242

19. Wikle, H., Kottilingam, S., Zee, R., and Chin, B. 2001. Infrared sensing techniques for penetration depth control of the submerged arc welding process. Journal of Material Processing Technology 113(13): 228-233. DOI: 10.1016/S0924-0136(01)00587-8

20. Vorman, A. R., and Brandt, H. 1976. Feedback control of GTA welding using puddle width measurement. Welding Journal 55(9): 742-749.

21. Ohshima, K., Yamamoto, M., Tanii, T., et. al. 1992. Digital control of torch position and weld pool in MIG welding using image processing device. IEEE Transactions on Industry Applications 28(3): 607-612. DOI: $10.1109 / 28.137446$

22. Pietrzak, K. A., and Packer, S. M. 1994. Vision-based weld pool width control. Journal of Engineering for Industry-Transactions of ASME 116(1): 86-92. DOI: 10.1115/1.2901813
23. Song, J. B., and Hardt, D. E. 1994. Dynamic modeling and adaptive control of the gas metal arc welding process. ASME J. Dy namic Syst., Meas., Contr. 116(3): 405-413. DOI: 10.1115/1.2899235

24. Barnett, R. J., Cook, G. E., Damrongsak, D., et al. 1998.

Through-the-arc sensing and control in pulsed gas metal arc welding. ASM Proceedings of the International Conference: Trends in Welding Research. Pine Mountain, Ga. 1068-1072.

25. Bicknell, A., Smith, J. S., and Lucas, J. 1994. Arc voltage sensor for monitoring of penetration in TIG welds. IEE Proceedings: Science, Measurement and Technology 141(6): 513-520. DOI: 10.1049/ipsmt:19941144

26. Wang, J. Y., Kusumoto, K., and Nezu, K. 2003. Microweld penetration monitoring techniques by arc sensing. Proceedings of the 2003 IEEE/ASME International Conference on Advanced Intelligent Mechatronics 2: 1027-1030. DOI: 10.1109/AIM.2003.1225483

27. Liu, Y. K., Shao, Z., and Zhang, Y. M. 2014. Learning human welder movement in pipe GTAW: A virtualized welding approach. Welding Journal 93(10): 388-s to 398-s.

28. Liu, Y. K., Zhang, Y. M., and Kvidahl, L. 2014. Skilled human welder intelligence modeling and control: Part I - Modeling. Welding Journal 93(2): 46-s to 52-s.

29. Liu, Y. K., Zhang, Y. M., and Kvidahl, L. 2014. Skilled human welder intelligence modeling and control: Part II - Analysis and control applications. Welding Journal 93(5): 162-s to 170-s.

30. Liu, Y. K., Zhang, W. J., and Zhang, Y. M. 2013. Adaptive neuro-fuzzy inference system (ANFIS) modeling of human welder's response to 3D weld pool surface in GTAW. Journal of Manufacturing Science and Engineering-Transactions of the ASME 135: 0210101-02101011.

31. Bates, B. E., and. Hardt, D. E. 1985. A real-time calibrated ther mal model for closed-loop weld bead geometry control. Journal of Dynamic Systems, Measurements, and Control 107: 25-33.

DOI:10.1115/1.3140703

32. Nguyen, N. T., Mai, Y. W., Simpson, S., et al. 2004. Analytical approximate solution for double ellipsoidal heat source in finite thick plate. Welding Journal 83(3): 82-s to 93-s.

33. Rosenthal, D. 1941. Mathematical theory of heat distribution during welding and cutting. Welding Journal 20(5): 220-s to 234-s.

34. Goldak, J. A., Chakravarti, A., and Bibby, M. 1984. A new finite element model for welding heat sources. Metallurgical Transactions B Vol. 15B, p. 299. DOI: 10.1007/ BF02667333

35. Eagar, T. W., and Tsai, N. S. 1983. Temperature fields produced by traveling distributed heat sources. Welding Journal 62(12): 346-s to 355-s.

36. Saeed, G., and Zhang, Y. M. 2008. Weld pool surface depth measurement using a calibrated camera and structured light. Measurement Science and Technology 18: 2570-2578. DOI:10.1088/09570233/18/8/033

37. Song, H. S., and Zhang, Y. M. 2007. Three-dimensional reconstruction of specular surface for gas tungsten arc weld pool. Measurement Science \& Technology 18: 3751-3767. DOI:10.1088/09570233/18/12/010

38. Liu, Y. K., Zhang, W. J., and Zhang, Y. M. 2015. Nonlinear modeling for 3D weld pool characteristic parameters in GTAW. Welding Journal 94(7): 231-s to 240-s.

39. Zhang, W. J., Liu, Y. K., Wang, X. W., and Zhang, Y. M.2012. Characterization of three-dimensional weld pool surface in gas tungsten arc welding. Welding Journal 91(7): 195-s to 203-s.

SHAO JE WU is with the Harbin Institute of Technology, Harbin, China, and the University of Kentucky, Lexington, Ky. HONG MING GAO is with the Harbin Institute of Technology, Harbin, China. WEI ZHANG is with The Ohio State University, Columbus, Ohio. YU MING ZHANG (ymzhang@engr.uky.edu) is with the University of Kentucky, Lexington, $\mathrm{Ky}$. 